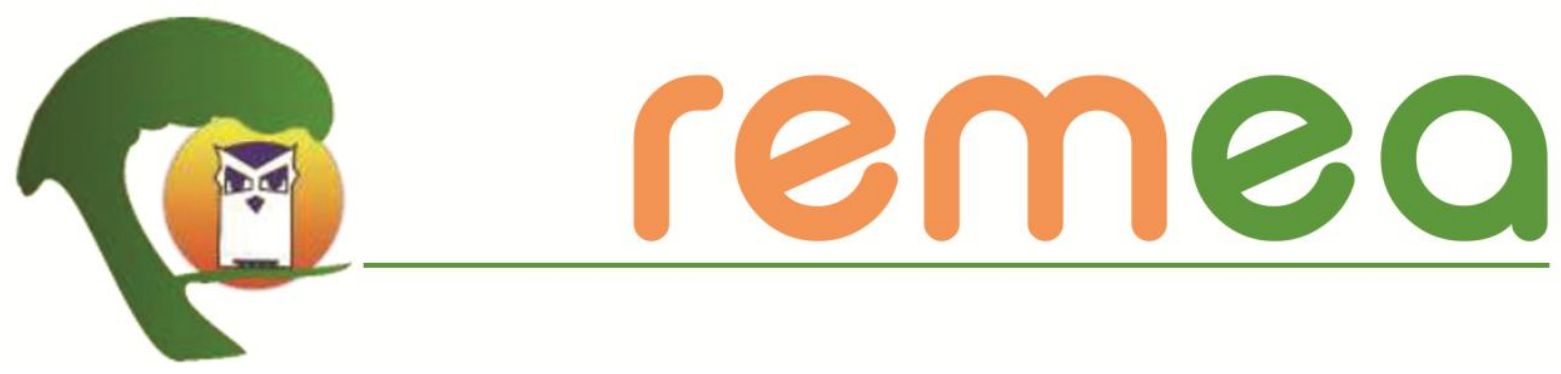

\title{
Formação de valores pessoais pró-sociais no ambiente escolar
}

\author{
Luiz Gonzaga Lapa ${ }^{1}$ \\ Universidade de Brasília - UNB \\ ORCID: https://orcid.org/0000-0003-3488-947X \\ Cláudia Pato \\ Universidade de Brasília - UNB \\ ORCID: https://orcid.org/0000-0003-0324-2075
}

Resumo: Conflitos pessoais e socioambientais têm se revelado cada vez mais no ambiente escolar, resultando em ameaças à integridade dos envolvidos e danos ao patrimônio material e imaterial. Este estudo investigou os valores pessoais de estudantes de uma escola pública do DF, com vistas à formação de valores voltados ao bem comum. Inicialmente, um survey com todos os estudantes da escola ( $N=980 ; 51,2 \%$ meninas; média de idade = 13 anos) mapeou os valores e identificou os principais conflitos existentes; em seguida, a turma com maior índice de valores individualistas e relatos de conflitos foi selecionada para as oficinas vivenciais centradas na formação de valores pró-sociais. Por fim, um survey combinado com rodas de conversa e entrevistas avaliaram as mudanças nos valores desses estudantes. Os resultados revelaram a manifestação de valores que transcendem os interesses egoísticos e um ambiente escolar mais solidário e colaborativo, evidenciando o potencial desse processo formativo para as transformações das relações interpessoais e socioambientais.

Palavras-chave: Valores pessoais, formação de valores, educação ambiental.

\section{Formación de valores personales prosociales en el entorno escolar}

Resumen: Los conflictos personales y socioambientales se han manifestado cada vez más en el ambiente escolar, lo que resulta en amenazas a la integridad de los involucrados y daños al patrimonio material e inmaterial. Este estudio investigó los valores personales de los estudiantes de una escuela pública del Distrito Federal, a fin de formar valores orientados al bien común. Inicialmente, una encuesta con todos los estudiantes de la escuela ( $N=980 ; 51,2 \%$ niñas; edad media = 13 años) mapeó los valores e identificó los principales conflictos existentes; luego, la clase con mayor índice de valores individualistas y relatos de conflicto fue

\footnotetext{
${ }^{1}$ Doutorado em Educação pela Universidade de Brasília, docente da Educação Básica e ensino Superior. Experiência como gestor de escola de ensino médio da Secretaria de Estado de Educação do Distrito Federal (SEEDF) e diretor pedagógico da Faculdade UniReal. E-mail:lapalipe@gmail.com

${ }^{2}$ Doutorado em Psicologia pela UnB, pós-doutorado em Psicologia Ambiental pela California State University San Marcos, professora da Faculdade de Educação da Universidade de Brasília (UnB), Coordenadora do Programa de Pós-Graduação em Educação da Faculdade de Educação da UnB. E-mail: claudiap@unb.br
} 
seleccionada para los talleres experienciales enfocados en la formación de valores prosociales. Finalmente, una encuesta combinada con círculos de conversación y entrevistas evaluó los cambios en los valores de estos estudiantes. Los resultados revelaron la manifestación de valores que trascienden los intereses egoístas y un ambiente escolar más solidario y colaborativo, destacando el potencial de este proceso de formación para la transformación de las relaciones interpersonales y socioambientales.

Palabras-clave: Valores personales, formación de valores, educación ambiental.

\section{Formation of personal pro-social values in the school environment}

Abstract: Personal and socio-environmental conflicts have increasingly revealed in the school environment, resulting in threats to the integrity of those involved and damage to material and immaterial heritage. This study investigated the personal values of students from a public school in the Federal District, with a view to forming values aimed at the common good. Initially, a survey with all students in the school $(\mathrm{N}=980 ; 51.2 \%$ girls; mean age $=13$ years) mapped the values and identified the main existing conflicts; then, the class with the highest index of individualistic values and conflict reports was selected for the experiential workshops focused on the formation of pro-social values. Finally, a survey combined with conversation circles and interviews evaluated the changes in the values of these students. The results revealed the manifestation of values that transcend selfish interests and a more supportive and collaborative school environment, highlighting the potential of this training process for the transformation of interpersonal and socioenvironmental relationships.

Keywords: Personal values, values formation, environmental education.

\section{Introdução}

Este trabalho é originário do Ecohumana - Grupo de Estudos e Pesquisa em Educação Ambiental e Ecologia Humana, da Faculdade de Educação da Universidade de Brasília - UnB, vinculado à Linha de Pesquisa Educação Ambiental e Educação do Campo EAEC, do Programa de Pós-Graduação em Educação, e foi apresentado no GT22 Educação Ambiental no XIV Encontro de Pesquisa em Educação da Região Centro-Oeste - Reunião Científica Regional da ANPED - Associação Nacional de Pós-Graduação e Pesquisa em Educação, realizada em Cáceres-MT. Importante salientar que essa reunião regional representou a primeira edição do GT22 Educação Ambiental da ANPED CO, cuja criação ocorreu na reunião anterior, realizada em Brasília-DF, em 2016, e foi resultado do movimento e da articulação entre dois grupos de estudos e pesquisas da região: o Grupo Pesquisador em educação ambiental, comunicação e arte - GPEA, da UFMT - Universidade Federal de Mato Grosso e o Ecohumana da UnB, cuja coordenadora é coautora do presente trabalho ${ }^{3}$.

\footnotetext{
${ }^{3}$ As primeiras coordenadoras do GT22 da ANPED CO foram a coordenadora do Ecohumana e a vicecoordenadora do GPEA/UFMT, que se alternaram entre coordenadora e vice-coordenadora do GT desde a sua criação, a fim de consolidar o GT.
} 
O Ecohumana desenvolve estudos com a interface entre Psicologia Ambiental, Educação Ambiental crítica e Ecologia Humana centrados no modelo teórico denominado Valores-Crenças-Normas (STERN et al., 1995), na abordagem metodológica simbólica e vivencial (DANSA; PATO; CORRÊA, 2014) e no método de autoconfrontação de valores (ROKEACH, 1973), tendo como referência a interdependência da relação eu-outro-planeta. As experiências e os conhecimentos acumulados há quase duas décadas sustentam a centralidade dos valores humanos, seja no nível individual, seja no nível social ou no cultural, para a compreensão das relações humano-socioambientais nos distintos contextos, assim como para a formação da cidadania planetária. O foco dos estudos tem sido, principalmente, sobre os sistemas de valores e de crenças dos participantes nos distintos contextos formativos pesquisados, de caráter longitudinal ou transversal, usando-se uma abordagem multimetodológica, que basicamente se estrutura em três etapas. A primeira se constitui num processo de diagnóstico para o mapeamento do sistema de valores e de crenças, além de demais aspectos relevantes para o estudo. Na segunda etapa são realizadas oficinas vivenciais para intervenção na realidade, com vistas à formação de um sistema de valores e de crenças consonantes com uma concepção mais ecocêntrica e biosférica, em que os participantes se percebam como parte da natureza, construam ou fortaleçam valores que envolvem os interesses do bem comum e coletivo e assumam a corresponsabilidade pelo cuidado ambiental, promovendo transformação em suas relações socioambientais. Na última etapa se faz a avaliação do processo e a comparação com o diagnóstico, a fim de se verificar as transformações alcançadas e em processo. Além disso, são fomentadas ações de planejamento e mobilização coletiva para a continuidade do processo formativo iniciado, com vistas ao desenvolvimento do pensamento crítico e reflexivo, assim como a formação ou a consolidação do sistema de valores e de crenças.

Com base nos estudos desenvolvidos pelo Ecohumana e tendo como foco o ambiente escolar e seus principais atores, os estudantes e os professores, apresenta-se a seguir uma pesquisa de método misto, que buscou investigar os valores de estudantes, com vistas a contribuir para a construção de um sistema de valores centrado no respeito ao outro 
nas suas distintas manifestações e na solução de conflitos relatados por professores de uma escola pública do Distrito Federal.

\section{O presente estudo}

Os conflitos pessoais e socioambientais têm se revelado cada vez mais no ambiente escolar, resultando em ameaças à integridade dos envolvidos e danos ao patrimônio material e imaterial. Tais conflitos sugerem o predomínio de valores e crenças mais individualistas, a falta de empatia e solidariedade entre os atores envolvidos nesse contexto, assim como revelam a degradação do ambiente escolar e de seu entorno. Com frequência é possível observar a intolerância e a incapacidade de lidar com conflitos nesses contextos, o que pode fomentar relações conturbadas nas escolas. Em geral, tais situações são compreendidas como resultantes de crises de valores, causando conflitos pessoais, desrespeito às normas e regras de convivência, entre outros. Uma escola estruturada com base em um sistema de valores inclusivo, que considere os interesses da coletividade mais ampla, incluindo as distintas formas de vida, deve reconhecer o papel central da educação na formação de valores, para favorecer a criação de sociedades sustentáveis, apoiadas na equidade, na solidariedade, na empatia, visando a transformação humana para a proteção da vida e do bem comum, assumindo assim, o seu protagonismo (REIS; SCHWERTNER, 2021).

No ambiente escolar, projetos que enfatizem valores humanos de autotranscendência, tais como os acima mencionados, possibilitam que estudantes tenham maior convivência com a diversidade, melhor compreensão do mundo que os rodeia e participação em questões relacionadas ao bem comum. Nessa perspectiva, a investigação dessas relações interpessoais na escola e a formação de valores pró-sociais e ecológicos nos estudantes tem como eixo orientador a educação ambiental, que visa "construir novas maneiras de os grupos sociais se relacionarem com o meio ambiente" (CARVALHO, 2011, p. 51) sendo mediadora da "construção social de novas sensibilidades e posturas éticas diante do mundo" (CARVALHO, 2011, p. 80).

Aelenei, Darnon e Martinot (2017) sugerem que atitudes como ajudar as pessoas em convívio próximo, ouvir os colegas e conservar um ambiente harmonioso, associados, 
portanto, aos valores de autotranscendência, possibilitam um efeito direto e positivo sobre o ambiente escolar. Indivíduos que apresentam atitudes transcendentais em relação à vida, que optam por dar ênfase aos interesses coletivos e valores de importância à autotranscendência de vida (VÖTTER; SCHNELL, 2019) contribuem para um ambiente saudável dentro e fora da escola.

Alinhada a essa perspectiva, Pato (2011) considera que os valores de autotranscendência, definidos como "a compreensão, a apreciação, a tolerância e a proteção do bem-estar de todas as pessoas e da natureza" (SCHWARTZ, 2017, p. 9), correspondem aos valores ecológicos. Em comum, ambos os tipos de valores, de autotranscendência e ecológicos, superam os interesses egoístas e estão voltados aos interesses coletivos mais amplos e ao bem comum, considerando as distintas manifestações da vida. Tais valores agrupam, entre outros, os de respeito ao próximo e à natureza.

Estudos dedicados à compreensão dessas interações humano-socioambientais com foco nas ações pró-ambientais e no engajamento crítico e consciente das pessoas para a construção de sociedades justas e sustentáveis têm afirmado a centralidade dos valores. Esses estudos revelam que esse sistema invisível de valores, crenças e atitudes pode tanto favorecer quanto dificultar ou inibir ações voltadas à proteção do patrimônio natural e sociocultural, assim como a construção de relações interpessoais mais pacíficas, entre outros (CHEN, 2015; CHUNG et al., 2019; JAGERS; MARTINSSON; MATTI, 2016).

Seria possível, então, que um processo educativo que ative valores de autotranscedência (ou ecológicos) contribua para a construção de mediação de conflitos e para a redução de comportamentos antissociais de estudantes? A ativação desses valores no ambiente imediato, da sala de aula e da escola, favorece a relação com a natureza e as demais formas de vida?

Dado a lacuna de estudos desse tipo no ambiente escolar, sobretudo no Brasil, aliados aos frequentes episódios de conflitos e de violência observados neste contexto, este estudo teve como objetivo mapear os valores pessoais de estudantes do ensino fundamental II de uma escola pública e desenvolver um processo de formação em valores, com ativação dos de autotranscendência (SCHWARTZ, 1992, 2005, 2012). Espera-se, assim, 
promover relações interpessoais mais harmoniosas e favorecer um ambiente escolar mais construtivo e educativo nos níveis pessoal, social e ambiental.

\section{Valores humanos e educação}

A educação é considerada um dos principais agentes de formação e transmissão de valores (COSTA, 2006). Uma educação orientada pelos valores humanos pode promover reflexões e discussões diversas, contribuindo para o desenvolvimento de um pensamento crítico e inclusivo, sobretudo se considerar a formação integral do individuo, neste caso, dos estudantes. Assim, uma educação centrada em valores pode promover a transformação dos estudantes e, consequentemente, de suas relações e inter-relações, visto os valores serem centrais tanto no sistema pessoal quanto no cultural e social e influenciarem as crenças, as atitudes e os comportamentos das pessoas e dos grupos sociais, entre outros (SCHWARTZ, 1992, 2005).

De acordo com Mondal (2017), a educação é um processo essencial para que valores orientados para interações sociais, tais como convivência, harmonia, cooperação, respeito e ajuda mútua, possibilitem que estudantes melhorem a qualidade de vida, podendo formar a base de seu caráter e desenvolver sua personalidade. Na escola, estudos diários sobre valores positivos devem ser fortalecidos e praticados visando mudanças de comportamentos (KARA; TEKIN, 2017).

Shrivastava (2017) considera que a sociedade se tornou dinâmica devido ao processo de modernização, incluindo a escola. Para ele, valores humanos como honestidade, sinceridade, moralidade e paz estão sendo afetados pelas diferenças entre classes sociais e desigualdade de gênero, entre outros. Portanto, o autor considera necessário olhar para os valores como parte integrante do sistema educacional como um todo.

É importante, no entanto, distinguir valores de moral. Enquanto a moral está associada à compreensão do que é certo ou errado, valores são entendidos como o que é importante para cada indivíduo, podendo ou não estar alinhados às expectativas da sociedade, e se originam das necessidades humanas básicas: biológica (de sobrevivência), social (de pertencimento grupal e interação social) e psicológica (de bem-estar e 
crescimento pessoal) (Schwartz, 1992; 2005). Nessa perspectiva, aquilo que é importante para uma pessoa não é necessariamente importante para outras. Mesmo quando algo for igualmente importante para um coletivo, não necessariamente terá o mesmo nível de importância entre as pessoas. Além disso, os valores pessoais estão vinculados às emoções, sejam elas positivas ou negativas. A seguir, se apresenta o modelo teórico de valores de Schwartz, que orientou o presente estudo.

\section{A Teoria de Valores Humanos de Schwartz}

Com base em estudos acumulados desde os anos 50 por psicólogos sociais, Schwartz definiu valores como metas desejáveis, que transcendem situações e contextos específicos (transituacionais), servem como guias orientando na seleção, na avaliação e nas decisões e são ordenados por ordem de importância em um sistema dinâmico e hierárquico. Essa estrutura dinâmica e hierárquica revela compatibilidades e conflitos potenciais se, em um determinado contexto, dois valores que compartilhem metas próximas ou que sejam opostos entre si são ativados simultaneamente. Por exemplo, a busca do sucesso pessoal pode conflitar com a busca do bem-estar de outras pessoas que necessitam ou dependem de sua ajuda. Por sua vez, essa busca de sucesso pode ser compatível com a busca de status e prestígio pessoal e social.

Schwartz (1992, 2005) evidenciou que essa estrutura é circular e universal, inicialmente distinguindo 10 tipos de valores: poder, realização, hedonismo, estimulação, autodireção, universalismo, benevolência, tradição, conformidade e segurança. Segundo Schwartz (2006) essa estrutura pode ser resumida em duas dimensões ortogonais: uma que agrega valores de autopromoção (poder, realização, hedonismo) $x$ valores de autotranscendência (universalismo e benevolência) e outra que agrega valores de abertura à mudança (hedonismo, estimulação, autodireção) x valores de conservação (tradição, conformidade, segurança). Os valores de autopromoção são considerados individualistas, por expressarem motivações de interesse exclusivamente pessoal, enquanto os valores de autotranscendência expressam motivações de interesses mistos, envolvendo o pessoal e o coletivo, tanto do grupo social primário quanto do mais amplo e as distintas formas de vida. 
Essa dimensão ortogonal é a que interessa para o presente estudo, especialmente os valores de autotranscedência.

Os valores de autotranscendência são compostos pelos valores de universalismo e benevolência. As motivações expressas pelos valores de universalismo são: compreensão, tolerância, respeito e proteção do bem-estar de todas as pessoas e da natureza. Já as dos valores de benevolência são: preservação e intensificação do bem-estar das pessoas com quem mantêm contatos pessoais freqüentes (BILSKY, 2009). Alguns valores associados ao universalismo são: respeito, igualdade, mundo de paz, sabedoria, proteção do meio ambiente; os de benevolência se compõem em: ser prestativo, responsabilidade, lealdade, amizade (SCHWARTZ, 1992, 2005). A tabela 1 abaixo apresenta os 10 tipos de valores e suas definições, conforme postulado pela teoria.

Tabela 1: Tipos de valores de Schwartz $(1992,2005)$

\begin{tabular}{|c|c|c|}
\hline Dimensão & $\begin{array}{l}\text { Tipo } \\
\text { motivacional de } \\
\text { valor }\end{array}$ & Definição \\
\hline \multirow{2}{*}{ Autotranscendência } & Universalismo & $\begin{array}{l}\text { Compreensão, tolerância e proteção para } 0 \\
\text { bem estar de todas as pessoas e da natureza }\end{array}$ \\
\hline & Benevolência & $\begin{array}{l}\text { Preservação e promoção do bem estar das } \\
\text { pessoas mais próximas }\end{array}$ \\
\hline \multirow{3}{*}{ Conservação } & Tradição & $\begin{array}{l}\text { Respeito, compromisso e aceitação dos } \\
\text { costumes ou religião }\end{array}$ \\
\hline & Conformidade & $\begin{array}{l}\text { Restrição de ações, inclinações e impulsos } \\
\text { propensos a prejudicar outros ou regras e } \\
\text { normas }\end{array}$ \\
\hline & Segurança & $\begin{array}{l}\text { Segurança, harmonia e estabilidade da } \\
\text { sociedade, dos relacionamentos e do self }\end{array}$ \\
\hline \multirow{2}{*}{ Autopromoção } & Poder & $\begin{array}{l}\text { Status social e prestígio, controle ou domínio } \\
\text { sobre as pessoas ou recursos }\end{array}$ \\
\hline & Realização & $\begin{array}{l}\text { Sucesso pessoal por meio de demonstração de } \\
\text { competência de acordo com padrão social }\end{array}$ \\
\hline \multirow{3}{*}{ Abertura à mudança } & Hedonismo & Prazer e gratificação sensual para si mesmo \\
\hline & Estimulação & Excitação, novidade e desafio na vida \\
\hline & Autodireção & Pensamento e ação independentes \\
\hline
\end{tabular}


A teoria de valores de Schwartz é considerada robusta e é a mais utilizada para investigar valores nas áreas de ciências humanas e sociais. Recentemente, Schwartz et al. (2012) refinaram essa teoria, que após testada resultou em uma estrutura de 19 valores, subdividindo alguns valores dos 10 originais. Com isso, os autores consideram que melhoraram o poder explicativo dos valores para a compreensão das relações com crenças, atitudes, comportamentos, entre outros.

A teoria refinada expressa com maior precisão, que os valores formam um continuum motivacional circular (Figura 1), com bases motivacionais de compatibilidade e conflito. Estes procuram atender um conjunto maior de valores significativos, permitindo explicar um conjunto mais abrangente e específico de atitudes e crenças.

A Teoria Refinada de Valores contém 19 valores, distribuídos nas mesmas quatro dimensões originais: Autotranscendência, Conservação, Autopromoção e Abertura à mudança, conforme Figura 1. A dimensão de autotranscendência é formada por valores que indicam aceitação dos outros como iguais e a preocupação com o bem-estar de todos e com a natureza. Conservação contém valores que favorecem a estabilidade, a segurança nas relações com outros e instituições, obediência e tradições. Autopromoção indica valores para o sucesso individual e domínio sobre os outros e as coisas, promovendo interesses próprios. A dimensão abertura à mudança prevê valores com independência de pensamento, liberdade de ação e motivação para aventuras. 
Figura 1: Modelo estrutural circular dos valores da Teoria Refinada de Valores

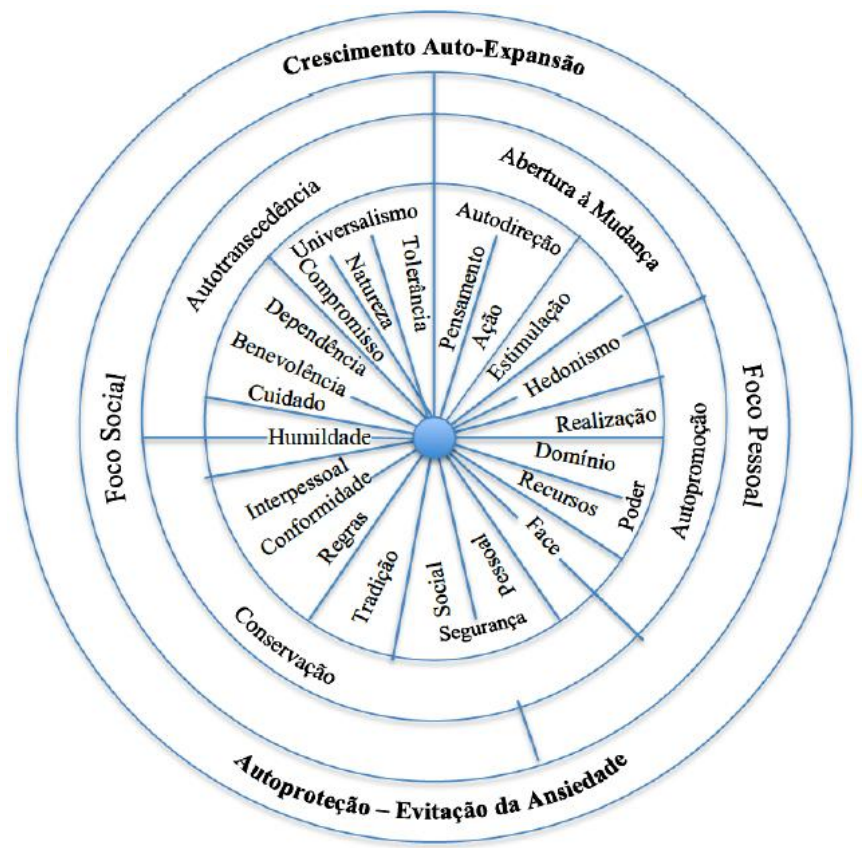

Fonte: TORRES; SCHWARTZ; NASCIMENTO, 2016, p. 343

Pelo refinamento da teoria de valores a dimensão Autotranscendência ampliou seus tipos de valores, passando a conter cinco valores, a partir das subdivisões de universalismo e benevolência, conforme ilustrado abaixo (Tabela 2).

Tabela 2: Valores de Autotranscendência da Teoria Refinada de Valores

\begin{tabular}{|c|c|c|}
\hline Dimensão & Tipo motivacional de valor & Definição \\
\hline \multirow{5}{*}{ Autotranscendência } & Universalismo tolerância & $\begin{array}{c}\text { Aceitação e compreensão daqueles } \\
\text { que são diferentes de si mesmo }\end{array}$ \\
\hline & Universalismo natureza & Preservação do ambiente natural \\
\hline & Universalismo compromisso & $\begin{array}{c}\text { Compromisso com a igualdade, } \\
\text { justiça e proteção de todas as } \\
\text { pessoas }\end{array}$ \\
\hline & Benevolência dependência & $\begin{array}{l}\text { Ser um membro correto e de } \\
\text { confiança do grupo }\end{array}$ \\
\hline & Benevolência cuidado & $\begin{array}{c}\text { A devoção ao bem-estar dos } \\
\text { membros do grupo }\end{array}$ \\
\hline
\end{tabular}

Fonte: SCHWARTZ et al. (2012). 
Ratifica-se que pessoas que possuem mais valores de autotranscendência tendem a ser tolerantes, cuidam da natureza e da sociedade e agem com benevolência em relação aos outros (BOJANOWSHA; URBANSKA, 2021). São também as pessoas que se voltam para ações de cooperação em vez de competição, pela realização de metas relacionadas aos valores de benevolência e universalismo, por exemplo, e os cuidados com a natureza (CALLAGHAN, 2020; CAVAGNARO, et al., 2021).

Para Tamayo (2007) o estudo de valores auxilia na compreensão da cultura, explicando os modos de agir de um povo, seus costumes, normas sociais, padrões de comportamentos, entre outros. O autor explica que a natureza dos valores permite realizar estudos sobre atitudes e comportamentos de um grupo, visando modificações comportamentais e transformações sociais, entre outros. Desse modo, podem contribuir com a educação ambiental, assim como na mediação de conflitos em ambientes escolares.

\section{Educação ambiental e o método vivencial na formação de valores}

A prática docente aponta que muitas escolas convivem com relações conturbadas entre os estudantes, podendo se configurar como um quadro iminente de violência escolar. Visando promover melhorias no ambiente escolar, a Educação Ambiental se propõe a despertar nos estudantes a vontade de construir o futuro com novas atitudes e novos comportamentos, com responsabilidade sobre suas ações (CARVALHO; SILVA JUNIOR, 2014), formando valores que os levem a reflexões sobre suas condutas e relações com as pessoas, com a natureza e com os diversos ambientes, primando por uma educação para a vida.

Essa perspectiva se coaduna com uma educação vivencial, onde as práticas possam ser refletidas, internalizadas e transformadas em comportamentos inovadores com novos modos de viver, abrindo oportunidades para emergirem novos sentimentos sobre novas relações, permitindo que o estudante construa novas formas de pensar e agir criticamente. Para Corrêa (2003, p. 120) o método vivencial permite que nas oficinas sejam "desenvolvidas atividades que abrem espaço para a pessoa exercitar sua sensibilidade e criatividade, 
possibilitando um entendimento maior de como ela vê e sente o mundo", compartilhando vivências, oportunizando "uma nova forma de compreender a realidade e nele interferir" ( $p$. 121).

No intuito de melhorar o conhecimento, desenvolver habilidades e formar valores o método vivencial tem sido utilizado para engajar os estudantes em ações que contribuam para a melhoria de sua comunidade local (DJONKO-MOORE et al., 2018). Essas práticas podem ocorrer em diversos ambientes, tais como parques, museus, bibliotecas, zoológico e outros lugares, permitindo que os estudantes tenham aprendizado autêntico enquanto se divertem (YOON et al., 2013).

Para a efetivação dessas práticas, considera-se as oficinas pedagógicas uma oportunidade de vivenciar situações concretas e significativas, segundo Paviani e Fontana (2009). Oficinas pedagógicas são estratégias de ensino-aprendizagem em que ocorrem “apropriação, construção e produção de conhecimentos teóricos e práticos, de forma ativa e reflexiva" (PAVIANI; FONTANA, 2009, p. 78). Dansa, Pato e Correa (2014), afirmam que as oficinas pedagógicas simbólicas e vivenciais, fundamentadas na perspectiva da educação ambiental e ecologia humana e na compreensão freiriana de que todo educador é simultaneamente educando, oferecem "uma base de sustentabilidade para a consolidação das relações democráticas no exercício da cidadania" (p. 213).

\section{Metodologia da pesquisa}

A presente pesquisa utilizou o método misto (CRESWELL, 2010) e foi desenvolvida em três etapas. Na primeira, quantitativa, fez-se o mapeamento dos valores pessoais de todos os estudantes de uma escola da rede pública do Distrito Federal por meio de um survey. Em seguida, a fase qualitativa consistiu na realização de um processo pedagógico de formação de valores de autotranscendência, por meio de oficinas vivenciais com duas turmas. Por fim, na terceira etapa, foi feito um novo levantamento dos valores pessoais com os participantes das oficinas da etapa dois, utilizando-se um survey.

\section{Os participantes}


Os participantes eram estudantes de uma escola pública do ensino fundamental II do Distrito Federal dos dois turnos: matutino e vespertino. Da etapa 1, participaram 980 estudantes, dos quais 51,2\% meninas, com média de idade de 13 anos. Da etapa 2 participaram duas turmas, com um total de 64 estudantes, dos quais 55,6 \% eram meninas. A média de idade foi igualmente de 13 anos.

\section{Os instrumentos utilizados}

Para o mapeamento dos valores foi utilizado o instrumento reduzido do Perfil de Valores Pessoais de Schwartz: o PQ21 - Portrait Questionaire. Apresenta 21 frases curtas, que descrevem pessoas com desejos e aspirações diversas, representando os dez tipos de valores individuais do modelo teórico de Schwartz (2005). Os participantes devem avaliar o grau de similaridade entre eles e as pessoas descritas nas frases e, usando uma escala tipo Likert de 6 pontos ( 1 = essa pessoa é muito parecida comigo a $6=$ essa pessoa não se parece nada comigo), escolher a opção que mais se adequar.

Em seguida foram incluídas duas questões abertas para complementar com a percepção dos estudantes acerca dos seus valores. Ao final, foram solicitados os dados sociodemográficos, como turma, idade e sexo.

As oficinas tiveram como eixo central os valores de respeito, solidariedade e empatia e o princípio da integração e interdependência entre "eu, outro e planeta" (natureza), conforme Dansa, Pato e Corrêa (2014). Assim, cada valor foi ativado em suas dimensões da própria pessoa (estudante), do outro (colegas, professores, família) e do planeta (plantas e animais do entorno da escola, de suas casas, suas cidades, por exemplo) de forma integrada. Essas oficinas foram estruturadas da seguinte forma: inicialmente uma sensibilização dos participantes para o tema; a mobilização com dinâmicas grupais, jogos e brincadeiras que envolvessem o tema e os valores (respeito, solidariedade e empatia) em suas distintas manifestações; a produção criativa que refletisse o vivenciado; a apresentação no grande grupo, para um panorama geral e a autoconfrontação das percepções individuais e do pequeno grupo; uma roda de conversa para avaliação do processo e síntese dos principais aspectos destacados, fomentando o debate coletivo. 
Os registros no diário de campo, com as observações do processo durante as oficinas e as reflexões que emergiram dessas observações, foram complementares para as análises dos dados.

\section{Os procedimentos}

A pesquisa foi autorizada pela equipe gestora da escola, com anuência de professores e pais dos estudantes. O primeiro questionário (survey), para o mapeamento dos valores, foi aplicado a 1.000 estudantes de toda a escola (83,33\% do total de alunos). Com base nas análises desses dados foram selecionadas 02 turmas, que apresentaram as médias mais baixas nos tipos de valores de autotranscendência. Os alunos dessas duas turmas foram convidados a participar da segunda etapa, das intervenções pedagógicas, doravante denominadas OPV (oficinas pedagógicas vivenciais).

Foram realizadas 20 oficinas em cada uma das turmas, ao longo de dois meses, por meio de dinâmicas cooperativas e explorando os valores pouco vivenciados no cotidiano da sala de aula, bem como os conflitos ocorridos recentemente na escola. Os valores de respeito (a si, ao outro e ao planeta, em suas múltiplas manifestações, como ao colega, ao professor, ao patrimônio escolar, aos animais, às plantas, entre outros), solidariedade e empatia foram o eixo condutor desse processo.

Ao término das oficinas foi aplicado um novo questionário contendo os mesmos itens do primeiro (PQ21), para comparar com os resultados obtidos no questionário anterior.

\section{As análises dos dados}

Os dados quantitativos foram analisados com o uso do SPSS - Statistical Package for Social Sciences - software de análise estatística, versão 20.0. A etapa preliminar de análise consistiu na investigação dos escores das médias dos valores de autotranscendência, de acordo com os pressupostos para as análises multivariadas. Foram utilizadas as técnicas estatísticas de médias e correlações com o coeficiente de Pearson. Os dados qualitativos foram analisados com base nas categorias temáticas vinculadas aos valores que foram 
ativados pelo processo das oficinas, complementados pela observação dos comportamentos e dos relatos dos participantes.

\section{Resultados e discussão}

Foram analisados os valores de universalismo e benevolência, que se constituem na dimensão de autotranscendência, tais como o respeito, a promoção para o bem-estar com os colegas da turma, da família, compreensão, tolerância, cooperação e cuidados com a natureza. Esses valores são orientados pelos interesses mistos (individuais e coletivos), pois se referem tanto ao cuidado consigo mesmo como com o dos outros, sejam pessoas ou a natureza.

\section{Primeira etapa da pesquisa}

Dos 1.000 questionários aplicados, 20 foram excluídos por apresentarem dados omissos, muito assimétricos ou apenas pontos extremos preenchidos. Os resultados apontaram uma média de 4,80 (DP $=0,76)$ para a dimensão de autotranscendência. $A$ amostra final de 980 é composta por estudantes de ambos os turnos ( $N=507$ do matutino; $N=473$ do vespertino), com média de idade de 13 anos, totalizando $51,2 \%$ de meninas e $48,8 \%$ de meninos.

Os resultados indicaram as duas turmas com menores médias na dimensão de autotranscendência: $6 \mathrm{~L}(\mathrm{M}=4,28 ; \mathrm{DP}=0,87)$ e $8 \mathrm{D}(\mathrm{M}=4,49 ; \mathrm{DP}=0,92)$, contrapondo-se às turmas com maiores médias: $8 C(M=5,07 ; D P=0,91)$ e $6 F(M=5,06 ; D P=8,90)$. As turmas com menores médias apresentavam problemas nas relações interpessoais, demonstrando ausência de valores voltados aos interesses coletivos e dificuldades em manter o bem-estar dos demais indivíduos das classes e da natureza. Essas turmas foram as escolhidas para a segunda etapa da pesquisa.

Dessa forma, as turmas 6L e 8D participaram da formação em valores (oficinas) com ênfase nos de autotranscendência - benevolência e universalismo - que representam valores voltados aos interesses coletivos, promovendo o bem-estar dos demais indivíduos e da natureza, como já mencionado anteriormente. 


\section{Segunda etapa da pesquisa - a formação em valores}

Os participantes da segunda etapa ( $N=64$ ) estão na faixa etária dos 12,2 aos 13,8 anos, no qual 55,6 \% são meninas. A turma $6 \mathrm{~L}$ participou com 31 estudantes e 8D com 33.

As oficinas foram realizadas ao longo de dois meses e enfatizaram, primordialmente, o valor respeito, visando à promoção do bem-estar de todos os estudantes, além do ambiente escolar e da natureza. A solidariedade e a empatia foram articuladas ao respeito, considerando-se a tríade eu-outro-planeta (natureza). Ao longo desse processo foram observadas as folhas-respostas com atividades orientadas aos participantes; suas falas; as reações e simbologias subjetivas e as reflexões nas rodas de conversa. As oficinas ocorreram com dinâmicas vivenciadas em equipes com o cunho cooperativo, de forma a provocar o envolvimento ativo e reflexivo dos participantes. A seguir, citam-se algumas dentre as atividades realizadas, para fins ilustrativos:

(a) Para sensibilizar os participantes e favorecer o autoconhecimento e a identidade grupal, utilizou-se a seguinte dinâmica: Os estudantes receberam uma folha com duas questões e responderam, sem se identificar, a primeira questão: “o que eu mais gosto de fazer é ...". Em seguida, as folhas foram redistribuídas de forma aleatória para que os participantes respondessem a segunda questão: "diga se você também gosta de fazer, ou não, o que está escrito na questão anterior".

No primeiro momento da atividade surgiram algumas conversas paralelas, brincadeiras e quebra de regras e normas previamente combinadas. Do mesmo modo, no segundo momento, após a redistribuição das folhas, as mesmas reações se manifestaram, talvez pelo ineditismo da atividade ou pela dificuldade em cumprir a tarefa, pois nunca tinham tido a experiência de ver suas "falas" expostas, ainda que anônimas. Mesmo assim, foi possível observar que não foram encontradas respostas com desrespeito aos outros colegas, ao contrário, continham respostas espontâneas, contrariando o clima aparentemente de desordem observado. Os resultados demonstram um possível respeito com o olhar do outro, além da descoberta de afinidades e diversidades no grupo. Posteriormente, na roda de conversa, foi feita discussão e reflexão sobre os diversos comportamentos apresentados e suas implicações para cada participante e para o grupo 
(coletivo). Essa sutil mudança no comportamento dos estudantes pode indicar reação às aprendizagens coletivas de reflexão pessoal provocadas pelas oficinas, em contraposição à ausência de atividades cooperativas na escola (DJONKO-MOORE et al., 2018).

(b) Uma outra dinâmica propôs que cada estudante escrevesse numa folha pendurada nas costas dos colegas, características que eles achavam mais importantes, mediante as palavras: VERDADE, AMOR, COLABORAÇÃO, LEAL, CONFIANÇA, RESPEITO, CARINHO, SINCERIDADE, HONESTO, CARÁTER, DINHEIRO, HUMILDADE, ENGRAÇADO, selecionadas pelas turmas. A análise nessa dinâmica perpassou pelo fato de todos os estudantes terem participado da atividade, sem tumulto nem quebra de regras, tampouco conversas ou brincadeiras inadequadas, como era usual com essas turmas antes do processo de intervenção. A demonstração pelo respeito mútuo na aceitação do outro começou a ser evidenciada na prática, além de valores como a cooperação e a solidariedade.

Corroborando com esses resultados, estudos com adolescentes árabes e judeus apontam correlações negativas entre o valor de universalismo e comportamento violento nas escolas (KNAFO; DANIEL; KHOURY-KASSABRI, 2008). Aliado a esse olhar, pesquisas demonstram que valores de autotranscendência podem melhorar o comportamento agressivo nos estudantes do ensino fundamental II (BENISH-WEISMAN, 2015). Esse achado sugere que uma das formas mais eficazes de promover o comportamento não agressivo nos estudantes é promover sua identidade e self como a promoção do bem-estar e ajuda mútua entre seus pares (BENISH-WEISMAN, 2015).

(c) Uma terceira dinâmica, intitulada "dança das cadeiras colaborativas", consistiu na retirada de uma cadeira a cada vez que a música parava, no entanto, com a regra de que ninguém deveria ser excluído da "brincadeira". O objetivo foi desafiá-los a ficarem todos sentados ao final, provocando que agissem de forma, criativa, solidária e cooperativa. Nenhum estudante saiu da dinâmica até permanecer uma única cadeira no centro da sala. Todos se divertiram e a dinâmica ocorreu com muita alegria, harmonia e respeito. Ao final, a discussão coletiva fomentou a reflexão e incentivou que se colocassem no lugar dos outros, fazendo o exercício de imaginar a mesma brincadeira com exclusão de pessoas e os 
convidou a comparar as distintas situações (de exclusão e de inclusão) para pensarem e avaliarem como se sentiam e como seria estar de "fora".

d) Por fim, uma dinâmica enfatizou as normas sociais a partir da percepção dos próprios estudantes, ressaltando o que "todo mundo faz", para provocar a reflexão e desafiá-los a pensar, sentir e fazer diferente. De acordo com os relatos dos estudantes, "todo mundo joga lixo no chão" [da escola]. Com base nisso, a questão provocadora foi: "Se todo mundo joga lixo no chão, eu também posso jogar, certo?". Usando desenhos e frases curtas os estudantes revelaram a compreensão da responsabilidade pessoal com as questões socioambientais, ao expressarem, por exemplo, "que temos que se preocupar com a situação do planeta em geral" e "que cada um deve fazer a sua parte", ao tempo em que se preocupam com os trabalhadores de limpeza urbana: "se os garis não tiverem lixo [para catar], manda eles para a escola que estão precisando". Ao final, o debate coletivo provocou a reflexão sobre o problema do descarte inadequado de lixo na escola, nas cidades, e os atores envolvidos, fomentando a importância do compromisso individual com as questões que envolvem o coletivo, entre outros aspectos favorecidos pela atividade.

É importante ressaltar que as oficinas e as dinâmicas promovidas nessa segunda etapa foram estruturadas do individual/interior para o coletivo/exterior, partindo sempre do "eu" e do ambiente mais próximo, no caso, a sala de aula e a turma, para, posteriormente, irradiar para o entorno e o ambiente mais amplo, como a escola e sua vizinhança, a cidade, o país e assim por diante, ativando os valores nos distintos níveis. Parte-se, portanto, do mais concreto e cotidiano para o mais abstrato e mais distante do "eu" participante.

Após cada intervenção com a ativação dos valores de autotranscendência foi possível perceber que começavam a emergir nos estudantes a disposição em aceitar informações; a tolerância à escuta do outro; o respeito às opiniões diferentes das suas. Do mesmo modo, os estudantes davam sinais de empatia e solidariedade com colegas, com professores e com a natureza, manifestando a busca pela cooperação e pelo cuidado. Com isso, indica-se que as escolas podem ter um papel crucial na prevenção da violência e no aumento da cooperação entre os estudantes implementando projetos que promovam 
valores universalistas (autotranscendência) para ajudar a reduzir comportamentos violentos (KNAFO; DANIEL; KHOURY-KASSABRI, 2008), bem como fomentar a proteção ambiental.

Ao longo dessa segunda etapa foi possível observar que os estudantes apresentaram comportamentos relacionados a cooperação, colaboração e ajuda mútua, enfatizando a confiança e a valorização de si mesmo, apontando para elevada autoestima. Há indícios que valores de autotranscendência promovem níveis mais altos de autoestima nas crianças e adolescentes, apontando a importância do contexto social para essas relações (BENISH-WEISMAN; DANIEL; MCDONALD, 2019).

\section{Terceira etapa da pesquisa}

Após a realização das oficinas, o segundo questionário foi aplicado aos estudantes que participaram desse processo formativo, com os mesmos itens do primeiro questionário. Os resultados revelaram um aumento nas médias dos itens da dimensão de autotranscendência, em relação ao anterior. Por exemplo, no item (8): "É importante para ela ouvir as pessoas que são diferentes dela. Mesmo quando não concorda com elas, a inda quer entendê-las", que pertence ao valor universalismo. No questionário 1 (antes das oficinas) obteve $M=3,76(D P=1,26)$ e no questionário 2 (depois das oficinas) foi $M=4,17$ $(\mathrm{DP}=0,79)$.

Observou-se o crescimento das médias de autotranscendência [M (antes OPV) = 4,21; $\mathrm{M}$ (depois OPV) $=4,65)$ ], indicando que os estudantes buscaram mais o bem-estar dos colegas; que os laços de amizades se estreitavam; que começavam a acreditar na igualdade de todos; e ter um pouco mais de respeito com as opiniões dos outros. Esse achado foi reafirmado pelos relatos dos professores, que constataram que os estudantes que participaram dessas oficinas estavam mais atentos e participativos em suas aulas e que os conflitos e os comportamentos mais violentos, como brigas e xingamentos, tinham sido significativamente reduzidos. Tais resultados corroboram que valores de autotranscendência podem melhorar comportamentos agressivos (BENISH-WEISMAN; DANIEL; MCDONALD, 2019) em estudantes. 
Estudos anteriores estabeleceram relações entre valores de autotranscendência e comportamentos pró-sociais em crianças e adolescentes como cooperação, ser útil e gentileza (BENISH-WEISMAN et al., 2019), fornecendo evidências que uma formação em valores pode modificar comportamentos antissociais. Do mesmo modo, estudos têm apontado que a ativação de valores de autotranscendência favorece a conexão com a natureza e promove mudanças de comportamentos, colaborando para a manifestação de atitudes e comportamentos pró-ambientais (DE GROOT; STEG, 2009; LUMBER; RICHARDSON; SHEFFIELD, 2017).

\section{Considerações finais}

O objetivo desta pesquisa foi identificar os valores de estudantes e desenvolver um processo de formação centrado nos valores de autotranscendência, por meio de intervenções pedagógicas, em um grupo de estudantes das séries finais do ensino fundamental de uma escola pública. Tal perspectiva está fundamentada na compreensão de que o desenvolvimento de valores desse tipo contribui para a formação de uma cidadania ecológica e planetária, favorecendo a construção de um sistema de valores e de crenças compatível com o cuidado e a proteção do patrimônio socioambiental da humanidade, com base no modelo teórico de Valores-Crenças-Normas (STERN et al., 1995), conforme apontam os estudiosos (FORNARA et al., 2020). Isso se alinha à concepção de educação ambiental, que aponta para a centralidade dos valores na compreensão da complexidade que envolve as interações humanos-socioambientais e no engajamento das pessoas com a natureza.

A educação ambiental está "intimamente associada à formação de valores e atitudes sensíveis à diversidade, à complexidade do mundo da vida e, sobretudo, a um sentimento de solidariedade diante dos outros e da natureza" (CARVALHO, 1998, p. 23), estando engajada na construção de uma nova cultura, que gera novos comportamentos com formação de sujeitos éticos e políticos, transformando as "relações sociais e culturais que constroem os modos individuais e coletivos de estar no mundo" (CARVALHO, 1998, p. 24). Nessa perspectiva, a formação centrada em valores humanos por meio de oficinas simbólicas e vivenciais, buscou transformar as relações interpessoais dos estudantes, 
visando melhorar seu comportamento em relação aos seus pares e ao mundo em que vivem (COSTA, 2006).

Nesse sentido, este trabalho encontrou na educação ambiental o suporte necessário para a compreensão dos cuidados com o indivíduo, com o coletivo e suas relações, permitindo dar novos significados aos conceitos de cidadania, qualidade de vida, liberdade, democracia, valores humanos e vivências. Tomando-se a escola como espaço socioambiental de construção do conhecimento, produção de sentidos e atitudes ecológicas (REIS; SCHWERTNER, 2021), espera-se ter contribuído para a construção do sujeito ecológico durante o processo formativo desenvolvido com esses estudantes.

A esse respeito, no que se refere aos valores de autotranscendência, esse estudo evidenciou que esses valores estão associados aos comportamentos pró-sociais e ecológicos dos estudantes, podendo ser ativados no desenvolvimento de oficinas pedagógicas voltadas para a formação de valores. No entanto, é importante reconhecer que, dado o caráter transversal do estudo, é possível que esses valores possam diminuir sua intensidade ao longo do tempo e não se consolidem, podendo, inclusive, retornar aos patamares encontrados inicialmente, caso as ações pedagógicas e formativas da escola não mantenham a ativação de tais valores, com vistas a sua construção e ao seu fortalecimento. Sabe-se que a estabilidade do sistema de valores ao longo do tempo exige que o processo de formação seja permanente. Nesse sentido, considera-se necessário que esse processo de ativação de valores de autotranscendência seja contínuo, sobretudo nessa faixa etária, em que o sistema de valores está em processo de formação e consolidação.

Igualmente importante é a continuidade de estudos desse tipo, que possam investigar outros públicos em diferentes culturas e contextos, como estudantes de outras faixas etárias, de outros níveis de ensino, de outras regiões ou de escolas particulares, bem como estudos longitudinais, que possam contribuir para a compreensão da formação do sistema de valores e sua implicação nas relações interpessoais e socioambientais. Assim, espera-se aprofundar a compreensão dessa complexa rede de relações e inter-relações, sob a perspectiva interdependente do eu, do outro e do planeta. 
No geral, esse estudo evidenciou o potencial do modelo teórico de Valores-CrençasNormas (STERN et al., 1995) e da abordagem pedagógica simbólica e vivencial com enfoque na ecologia humana para a educação de crianças brasileiras. Em especial, os resultados encontrados se mostram promissores para a educação ambiental. Espera-se, assim, contribuir para a construção de uma sociedade mais justa e sustentável.

\section{Referências}

AELENEI, Cristina; DARNON, Céline; MARTINOT, Delphine. Boys, girls, and the school cultural environment: Teachers' judgment and students' values, The Journal of Social Psychology, v. 157, n. 5, p. 556-570, 2017.http://dx.doi.org/10.1080/00224545.2016.1243514.

BENISH-WEISMAN, Maya. The Interplay Between Values and Aggression in Adolescence: A Longitudinal Study. Developmental Psychology, v. 51, n. 5, p. 677- 687, 2015. http://dx.doi.org/10.1037/dev0000015.

BENISH-WEISMAN, Maya; DANIEL, Ella; MCDONALD, Kristina L. Values and Adolescent SelfEsteem: The Role of Value Content and Congruence with Classmates. European Journal of Social Psychology, v. 50, n. 1, may, 2019.https://doi.org/10.1002/ejsp.2602.

BENISH-WEISMAN, Maya et al. The relations between values and prosocial behavior among children: The moderating role of age. Personality and Individual Differences, v. 141, p. 241247, 2019. https://doi.org/10.1016/i.paid.2019.01.019.

BILSKY, Wolfgang. A estrutura de valores: sua estabilidade para além de instrumentos, teorias, idade e culturas. Revista de Administração Mackenzie, v. 10, no 3. São Paulo, maio/junho, 2009. Disponível em: Acesso: 20 de junho de 2014.

BOJANOWSKA, Agnieszka; URBANSKA, Beata. Individual values and well-being: The moderating role of personality traits. International Journal of Psychology, 2021. https://DOI.org/10.1002/ijop.12751.

CALLAGHAN, Chris Willian. Do benevolent and altruistic supervisors have higher postgraduate supervision throughput? The contributions of individual motivational values to south african postgraduate supervision throughput. South African Journal of Higher Education. V. 34, n. 6, p. 27-51, 2020. https://dx.doi.org/10.20853/34-6-3888.

CARVALHO, Isabel Cristina de Moura. Em direção ao mundo da vida: interdisciplinaridade e educação ambiental / Conceitos para se fazer educação ambiental. Brasília: IPÊ - Instituto de Pesquisas Ecológicas, 1998. Cadernos de educação ambiental 2. 
CARVALHO, Isabel Cristina de Moura. Educação ambiental: a formação do sujeito ecológico. São Paulo: Cortêz, 5ạ.edição, 2011.

CARVALHO, Mirelly Gabrielly Mendes de; SILVA JUNIOR, Milton Gonçalves da.Análise da transversalidade da educação ambiental na fase II do ensino fundamental da rede pública municipal e estadual de Goiânia-GO. Revista Eletrônica de Educação da Faculdade Araguaia, v. 5, p.1- 13, 2014.

CAVAGNARO, Elena et al. Profiling for sustainable tourism: young travellers' selftranscendence values and motivations. European Journal of Tourism Research, v. 28, 2810. 2021.

CORRÊA, Rosângela Azevedo. Cultura, educação para, sobre e na paz. In: MILANI, Feizi M.; JESUS, Rita de Cássia D. P. (Orgs.) Cultura da paz: estratégias, mapas e bússolas. Salvador: INPAZ, 2003, PP. 97-141.

COSTA, Marília R. Maia. Valores e práticas no dia-a-dia da sala de aula. Rio de Janeiro: Wak editora, 2006.

CRESWELL, John W. Projeto de pesquisa: métodos qualitativos, quantitativos e misto. Tradução: Magda Lopes. 3a. ed. Porto Alegre: Artmed, 2010.

DANSA, Claudia; PATO, Claudia; CORRÊA, Rosângela. Educação Ambiental e Ecologia Humana: Contribuições para um debate. In: MARQUES, Juracy (org.). Ecologias Humanas. 1. ed. Feira de Santana: Universidade Estadual de Feira de Santana, 2014. p. 207-216.

DE GROOT, Judith I. M.; STEG, Linda. Morality and Prosocial Behavior: The Role of Awareness, Responsibility, and Norms in the Norm Activation Model Morality and Prosocial Behavior: The Role of Awareness, Responsibility, and Norms in the Norm Activation Model. The Journal of Social Psychology, [S. I.], v. 149, n. 4, p. 425-449, 2009. Disponível em: https://doi.org/10.3200/SOCP.149.4.425-449doi.org/10.3200/SOCP.149.4.425-449

DJONKO-MOORE, Cara et al. Using Culturally Relevant Experiential Education to Enhance Urban Children's Knowledge and Engagement in Science, Journal of Experiential Education , v. 41, n. 2, p. 137-153, 2018. https://DOI.org/10.1177/1053825917742164.

FORNARA, Ferdinando et al. The extended Value-Belief-Norm theory predicts committed action for nature and biodiversity in Europe. Environmental Impact Assessment Review, [S. l.], v. 81, n. May 2019, p. 106338, 2020. Disponível em:

https://doi.org/10.1016/j.eiar.2019.106338

JAGERS, Sverker C.; MARTINSSON, Johan; MATTI, Simon. The Environmental Psychology of the Ecological Citizen: Comparing Competing Models of Pro-Environmental Behavior*. Social 
Science Quarterly, [S. I.], v. 97, n. 5, p. 1005-1022, 2016. Disponível em:

https://doi.org/10.1111/ssqu.12313.

KARA, Ahmet; TEKIN, Hatice. The Investigation of Human Values Perceived from the Use of Social Media of Secondary School Students. Universal Journal of Educational Research, v. 5, n. 11, p. 1912-1925, 2017.http://DOI.org/10.13189/ujer.2017.051108.

KNAFO, Ariel; DANIEL, Ella; KHOURY-KASSABRI, Mona. Values as Protective Factors Against Violent Behavior in Jewish and Arab High Schools in Israel. Child Development, v. 79, n. 3, p. 652 - 667, may/june, 2008.

LUMBER, Ryan; RICHARDSON, Miles; SHEFFIELD, David. Beyond knowing nature: Contact, emotion, compassion, meaning, and beauty are pathways to nature connection. PLoS ONE, [S. I.], v. 12, n. 5, p. 1-24, 2017. Disponível em:

https://doi.org/10.1371/journal.pone.0177186

MONDAL, Bhim Chandra. Inculcating Human Values among School Students through Effective Teaching. Journal of Social Sciences, v. 13, n. 2, p. 102-107, 2017.

https://DOI.org/10.3844/jssp.2017.102.107.

PATO, Claudia. Valores ecológicos. In: CAVALCANTE, Sylvia e ELALI, Gleice A . (orgs)Temas básicos em Psicologia Ambiental. Petrópolis, RJ: Vozes, 2011.

PAVIANI, Neires Maria Soldatelli; FONTANA, Niura Maria. Oficinas pedagógicas: relato de uma experiência. Conjectura, Caxias do Sul, v. 14, n. 2, p. 77-88, maio/ago. 2009. Disponível em http://www.ucs.br/etc/revistas/index.php/conjectura/article/viewFile/16/15. Acesso em 10 jul 2021.

REIS, Geilson de Arruda; SCHWERTNER, Suzana Feldens. Educação Ambiental no Ensino Fundamental: aprendizagens estudantis e seus reflexos para além da escola. Revista Diálogo Educacional, Curitiba, v. 21, n. 69, p. 957-984, abr./jun. 2021. Disponível em http://dx.doi.org/10.7213/1981-416X.21.069.A008.

ROKEACH, Milton. The nature of human values. New York (USA): Free Press, 1973.

SCHWARTZ, Shalom H. Validade e aplicabilidade da Teoria de Valores. In: TAMAYO, Álvaro e PORTO, Juliana Barreiros (orgs.) Valores e comportamento nas organizações. Petrópolis, RJ: Vozes. 2005.

SCHWARTZ, Shalom H. et al. Universals in the content and structure of values: theoretical advances and empirical tests in 20 countries. In: ZANNA (org.) Advances experimental social psychology, v. 25, p. 1-64, 1992. San Diego, CA Academic Press. 
SCHWARTZ, Shalom H. et al. Refining the theory of basic individual values. Journal of Personality and Social Psychology, v. 103, n. 4, p. 663-688.

2012.https://doi.org/10.1037/a0029393.

SCHWARTZ, Shalom H. The Refined Theory of Basic Values. In: SAGIV, Lilach; ROCCAS, Sonia (org.). Values and Behavior.Taking a Cross Cultural Perspective. Cham, Switzerland: Springer International Publishing, 2017. p. 51-72

SHRIVASTAVA, Shailaj Kumar. Promotion of moral values through education. International Journal of Research in Social Sciences, v. 7, n. 6, June, 2017.

STERN, Paul C. et al. Values, Beliefs, and Proenvironmental Action: Attitude Formation Toward Emergent Attitude Objects. Journal of Applied Social Psychology, [S. I.], v. 25, n. 18, p. 1611-1636, 1995. Disponível em: https://doi.org/10.1111/j.1559-1816.1995.tb02636.x.

TAMAYO, Alvaro. Hierarquia de Valores Transculturais e Brasileiros. Psicologia: Teoria e Pesquisa, [S. I.], v. 23, n. SPECIAL, p. 7-15, 2007. Disponível em:

https://doi.org/10.1590/S0102-37722007000500003.

TORRES, Claudio Vaz; SCHWARTZ, Shalom H.; NASCIMENTO, Thiago Gomes. A Teoria de Valores Refinada: associações com comportamento e evidências de validade discriminante e preditiva. Revista PsicologiaUSP, v. 27, no. 2, p. 341-356, 2016.

VÖTTER, Bernadette; SCHNELL, Tatjana. Cross-Lagged Analyzes Between Life Meaning, SelfCompassion, and Subjective Well-Being Gifted Adultos. Mindfulness 10, p. 1294-1303, 2019.https://doi.org/10.1007/s12671-018-1078-x.

YOON, Susan A., et al. Scaffolding informal learning in science museums: How much is too much? Science Education, v. 97, p. 848-877. 2013. https://doi.org/10.1002/sce.21079. 